\title{
INCREASED WATER LEVELS DUE TO MORPHODYNAMIC CHANGES; THE LIMFJORD, DENMARK
}

\author{
Soeren Bjerre Knudsen ${ }^{1}$, Signe M. Ingvardsen ${ }^{1}$, Holger Toxvig Madsen ${ }^{1}$, Carlo Sorensen ${ }^{1}$ and \\ Bo Brahtz Christensen²
}

\begin{abstract}
The Limfjord is an estuary in Denmark between The North Sea and Kattegat. The Thyboroen Channel connects the fjord with The North Sea. The water levels in the western part of the Limfjord are strongly correlated with the water level in the sea at Thyboroen. Analyses revealed a close to threefold increase in the channel cross section over the last 100 years. This has led to a detailed investigation into the effects of the channel cross section on the extreme high water levels in the Limfjord now and in the future. For Lemvig in the western part of the Limfjord the water level with a return period of 100 years would have been $1.73 \mathrm{~m}$ with the 1958 channel bathymetry throughout the whole period and $1.99 \mathrm{~m}$ with the 2005 channel bathymetry. With the extrapolated 2060-bathymetry the 100 years water level will be $2.38 \mathrm{~m}$. A number of measures to counteract the consequences of this development have been evaluated.
\end{abstract}

Keywords: estuary; numerical modelling; high water levels

\section{INTRODUCTION}

The Limfjord is an estuary in Denmark between The North Sea and Kattegat, see Fig 1. The water level west of Loegstoer is strongly correlated with the water level in The North Sea at Thyboroen. Analyses revealed a close to threefold increase in the Thyboroen Channel cross section during the last 100 years. This fact has led to a detailed investigation of the consequences on the extreme high water levels in the Limfjord now and in the future. A number of measures to counteract the consequences have been evaluated.

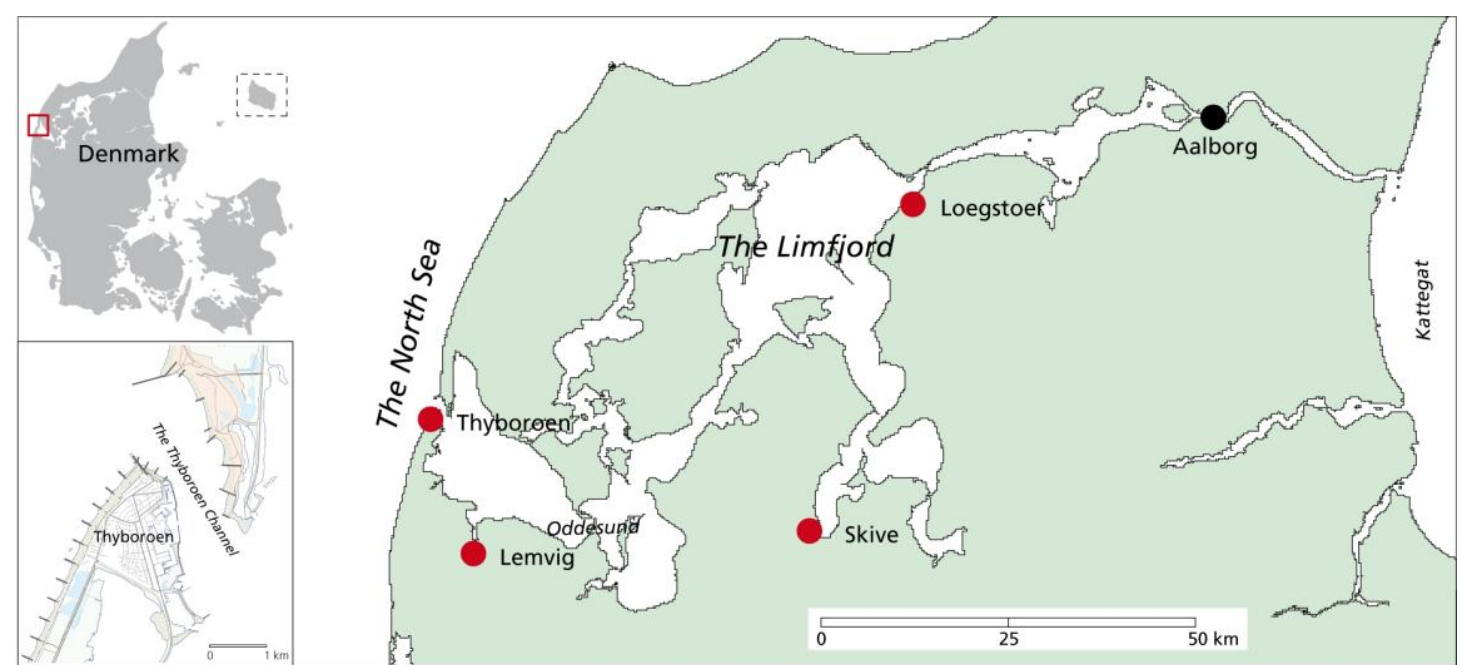

Figure 1. Location map.

\section{HISTORICAL OVERVIEW}

The Thyboron Channel is a result of a breach in the narrow land spit during a storm surge in 1862. Previous to this, the area had experienced a number of similar channels through the spit that were soon filled in by the large natural longshore sediment transport along the North Sea coast. However, after the 1862 incident it was decided to maintain this new channel to make easy access to the North Sea from the ports in the western part of the Limfjord.

Large groynes were used to maintain the channel opening. The first of these was corner groyne no. 59 built in 1875 , see fig. 2 . Before the end of the 19 th century the southern side of the channel was stabilized with groynes from no. 33 to no. 63. It was also necessary to stabilize the northern side and groyne no. 72 to no. 85 were built in $1905-08$.

\footnotetext{
${ }^{1}$ Danish Coastal Authority, Hoejbovej 1, DK-7620 Lemvig, Denmark, kdi@kyst.dk

2 DHI, Agern Allé 5, DK-2970 Hoersholm, Denmark, dhi@dhigroup.com
} 
The stabilization of the channel brought about the development of a small fishery port in 1914-17 on the south side of the channel. The port has grown steadily and is now one of the largest fishery ports in Denmark.

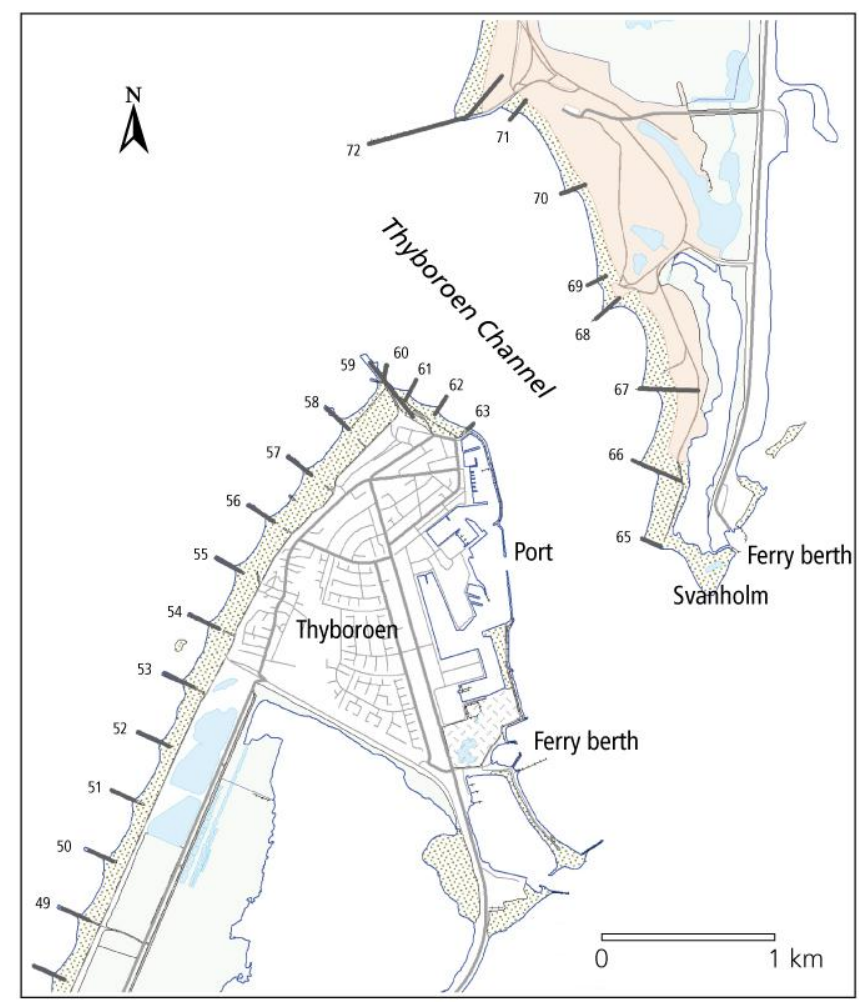

Figure 2. Detailed map of the channel area.

\section{MORPHOLOGICAL DEVELOPMENT OF THE CHANNEL}

\section{The Overall Development of the Channel}

The coast at Thyboroen is a sandy coast dominated by westerly wind and waves. On average, the wave height exceeds $2.5 \mathrm{~m}$ approximately 75 days per year. The tidal range is about $0.50 \mathrm{~m}$, and the high water level within a 100 year return period is $2.61 \mathrm{~m}$ outside the channel at the North Sea coast and $1.90 \mathrm{~m}$ in the port of Thyboroen, (Sorensen et al. 2007).

After the formation of the channel in the breach in 1862 the coastal retreat on the now two land spits north and south of the channel increased because the channel acted as a drain for the longshore sediment transport. Longshore transport was largest from the north and therefore the channel direction gradually changed from W-E to WNW-ESE. The sand transported through the channel was deposited in the Limfjord just east of the channel and a large flood tidal delta divided by narrow channels started to develop.

The building of groynes along the southern spit reduced the coastal retreat here and with that the longshore transport from the south. This made the longshore transport from the north still more dominating with the result that the channel direction turned to NW-SE.

The northern spit was stabilized with groynes along the North Sea in 1905-08. This reduced the south-going sediment transport towards the channel and therefore it was necessary to built two groynes at the north side of the channel in 1914-17 to protect this side from lee side erosion.

With all these groynes the overall plan form of the channel was fixed. However, there were still some changes going on. In Fig. 3 it is shown how the local spit Svanholm has developed since 1969. At this time Svanholm was a rather strong and apparently stable spit. By 1984 it had clearly grown weaker and by 2005 it had totally disappeared. The reason for this development is considered to be strongly influenced by the fact that dredging of nourishment sand took place close to the spit in the 1980's. 

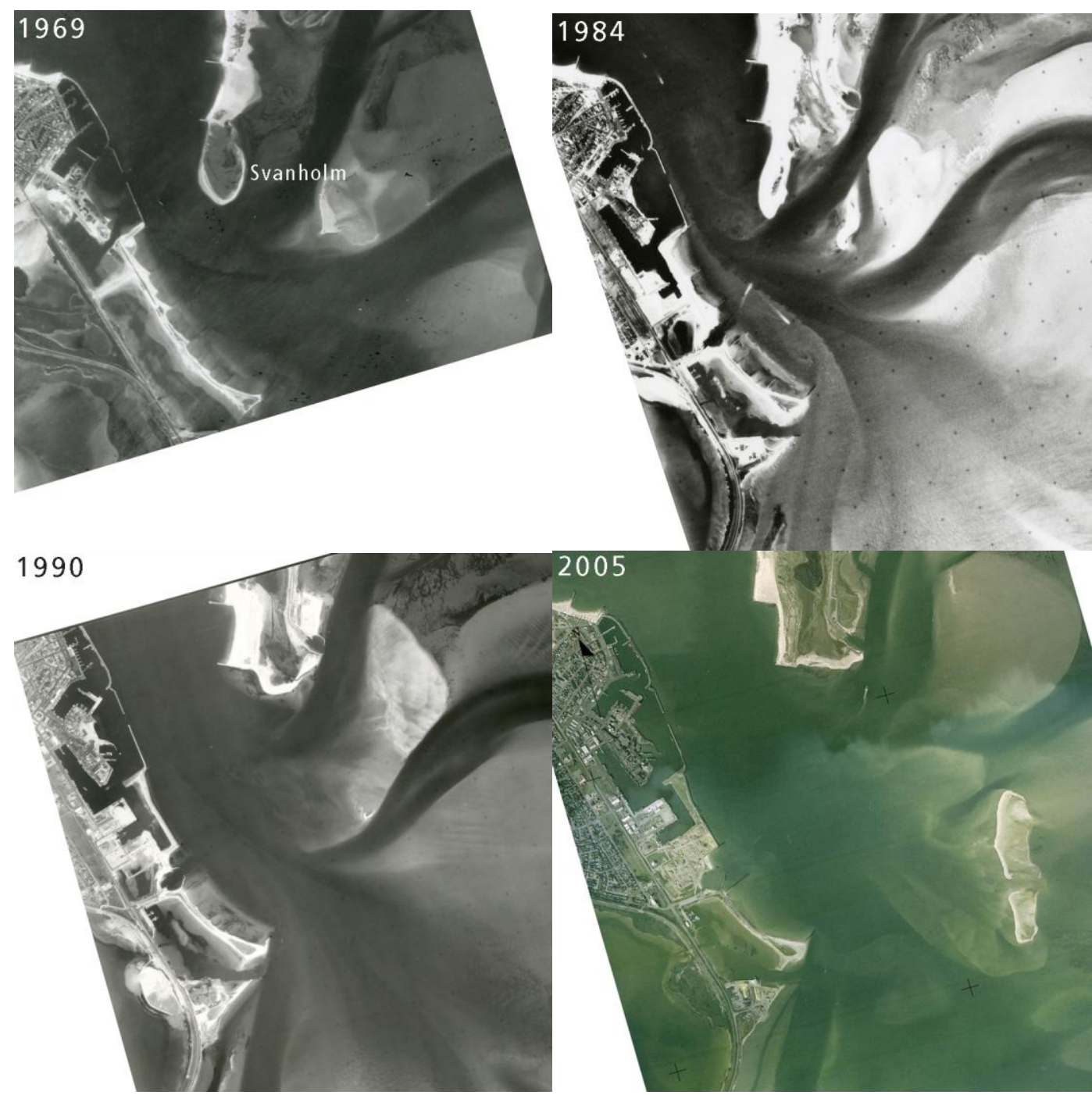

Figure 3. Aerial view of the Svanholm area in 1969, 1984, 1990 and 2005.

\section{The Development of the Channel Cross Section}

In 1914 the natural navigational depth in the channel was less than $5 \mathrm{~m}$. In 1956 the depth was $6 \mathrm{~m}$, in $19667 \mathrm{~m}$, in $19888 \mathrm{~m}$ and in 2000 it has grown to $9 \mathrm{~m}$. This fast development of the channel is illustrated by the curve in Fig. 4 showing the cross sectional area. Although the cross sectional area in short periods decreases the general trend is an increase of $150 \%$ from 1910 to 2005. 


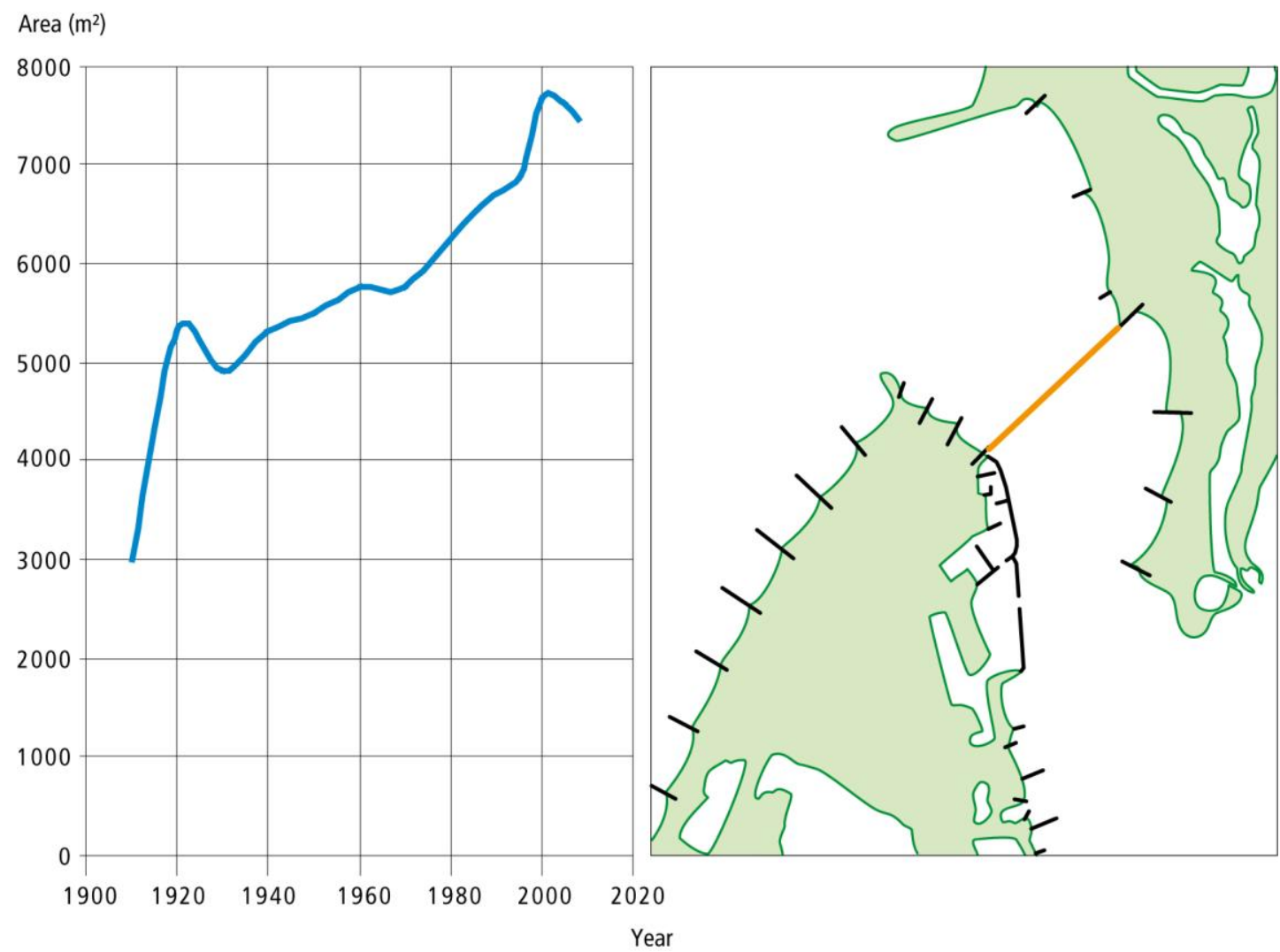

Figure 4. The increase in cross sectional area of the channel.

This development in the cross sectional area is seen in the rest of the channel as well. Calculations show that the net erosion in the channel between 1987 and 2005 was 250,000 $\mathrm{m}^{3} /$ year. However, this erosion is not evenly distributed over the channel area. A transgression of the channel has also taken place as can be seen in Fig. 5 .

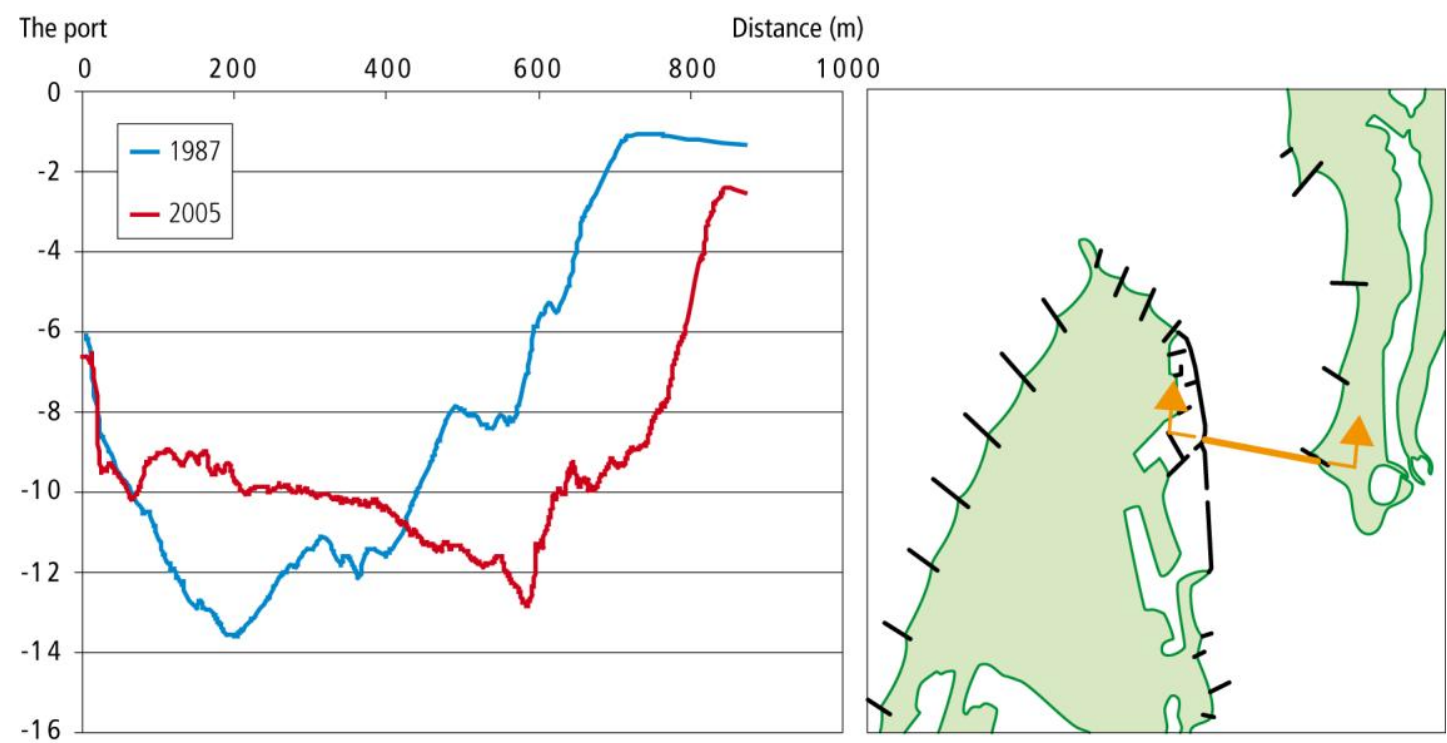

Depth $(\mathrm{m})$

Figure 5. The transgression of the channel between 1987 and 2005.

The deepest part of the channel has moved about $400 \mathrm{~m}$ away from the port towards the east. The main reason for this transgression is supposed to be the fact that Svanholm has disappeared so the ebb 
current has moved away from the port side of the channel. The transgression means that the lower depths remain beside the port. Since 2007 it has been necessary to carry out maintenance dredging in front of the port entrance to maintain a navigational depth of $9 \mathrm{~m}$. Another negative effect of the shallower depths beside the port is increased wave refraction. Large waves from the NW are refracted towards the port entrance. To prevent this extra wave energy entering the port it has been necessary to carry out regular dredging of the sand deposit in the channel at the northern end of the port.

Based on the channel development until now both the transgression and the increase in cross sectional area are expected to continue. The transgression can be reduced by extending the groynes at the east side of the channel but it is in practice impossible to move the channel back to its previous position in for instance 1987.

Some considerations have been made concerning the maximum cross sectional area of the channel. The question is if the maximum cross sectional area is determined by the tide or by the storm high water levels in The North Sea at Thyboroen. If it is the tide the maximum area of the channel when it is fully developed should be proportional to the tidal prism, see (Bijsterbosch 2003). The tidal prism is the tidal range multiplied by the area of the part of the Limfjord affected by the tide. The tide modelling described below gives the volume of the tidal prism. With this volume used in the formula the maximum channel area works out to be about $30 \%$ smaller than the actual channel area. This calculation shows that it is not the tide but the storm high waters in the sea which determine the size of the channel cross section. Based on the trend of the area curve in Fig. 4 the present channel area is far from its final maximum.

\section{The Effect of the Channel Changes on the High Water Levels in the Limfjord}

Water level data for Logstoer has been available since 1930. This high water data has been adjusted for the known sea level rise over the period and the trend in the heights analysed. The analyses showed an increase in the high water levels. This increase was of such a size that it was decided to analyse the problem in greater detail. Therefore it was decided to initiate numerical modelling with the purpose of being able to quantify the effect of the channel changes on the high water levels in the Limfjord.

\section{CALIBRATION OF THE MODEL}

\section{The Model}

The main purpose of this modelling is to investigate the effects of increased cross sectional area in the Thyboroen channel on the high water levels in the Limfjord. How much higher are the maximum water levels today in an extreme storm compared to the same storm 50 years ago and how much higher will the water levels be in the future for instance in 2060 ?

The modelling was carried out by DHI in close collaboration with The Danish Coastal Authority. The model used was MIKE $21 \mathrm{HD}$ which is a 2-dimensional hydrodynamic model. The whole Limfjord was modelled and the calculation grid was a combination of triangles and quadrangles. The quadrangular elements are typically used for the channels in the narrow parts of the fjord, while the triangles are used in the rest because they are more flexible. The bathymetry could be described in great detail because the modelled storms only had a duration of 4 days.

In the following the different modelling phases are briefly described.

\section{Modelling the Tide}

The main purpose of the tide modelling is to verify and document the quality of the hydrodynamic model. The tidal range is relatively small with $0.5 \mathrm{~m}$ in Thyboroen and $0.1 \mathrm{~m}$ at the Kattegat end of the fjord. The tide in the model is governed by the known tidal variations of the western and eastern boundaries. The quality of the model bathymetry and the bottom friction used are important for a good conformity between the modelled tide and the real tide.

Due to the highly detailed description of the models bathymetry the tidal modelling could give a determination of the best bottom friction. Manning numbers of 35, 40 and $45 \mathrm{~m} / 3 / \mathrm{s}$ were tested and 40 $\mathrm{m}^{1 / 3} / \mathrm{s}$ gave the best agreement between the model and real tide.

\section{The Influence of Waves at the Channel Entrance}

During storms there are always high waves at the entrance of the Thyboroen channel. To analyse the wave impact on the channel inflow during a storm a wave model was set up for the area just outside the channel entrance. With wave data from the nearby wave gauge the tensor for the radiation stress was 
determined. A few storms were modelled with and without this stress tensor and it was concluded that it was not necessary to include the radiation stress.

\section{Calibration of the Model}

For calibration of the model six recent storms were used together with a channel bathymetry from 2005. To be of an acceptable quality the modelled water levels must not deviate beyond $20 \mathrm{~cm}$ from the measured water levels. This quality control was possible for the four stations with water level registrations: Thyboroen, Lemvig, Logstoer and Skive, see Fig. 1.

There is a large variation in the wind field over the Limfjord area. However, it was decided to use the same wind field over the whole area. Based on the tests it was chosen to use a wind field with velocity as in Thyboroen and with a direction as the average of the directions in Thyboroen and Aalborg.

For the wind friction factor an interpolation between 0.001255 and 0.003595 for wind velocities of $7 \mathrm{~m} / \mathrm{s}$ and $43 \mathrm{~m} / \mathrm{s}$ respectively was used. This is a deviation from the standard practice where the increase in the wind friction factor stops at $25 \mathrm{~m} / \mathrm{s}$.

\section{SENSITIVITY ANALYSES WITH THE MODEL}

\section{Introduction}

To improve the general understanding of what changes in the bathymetry of the channel and the area inside mean for the high water levels in the Limfjord a number of sensitivity tests have been run. The effects of changes in storm intensity and mean water level have also been tested. In the tests two historical storms were used. Only the results for the most extreme storm from January 2005 are presented below.

\section{Sensitivity for a Change of the Channel Depths}

The channel depths and related cross sectional areas are crucial for the high water levels in the Limfjord during storms. Therefore a depth reduction of $25 \%$ as well as a depth increase of $25 \%$ were examined. The results are shown in Table 1.

\begin{tabular}{|c|c|c|}
\hline Station & Depths increased by $25 \%$ & Depths reduced by $25 \%$ \\
\hline Thyboroen port & $12 \mathrm{~cm}$ & $-14 \mathrm{~cm}$ \\
\hline Lemvig & $10 \mathrm{~cm}$ & $-17 \mathrm{~cm}$ \\
\hline Logstoer & $1 \mathrm{~cm}$ & $-2 \mathrm{~cm}$ \\
\hline Skive & $5 \mathrm{~cm}$ & $-7 \mathrm{~cm}$ \\
\hline
\end{tabular}

It appears that a depth increase in the channel causes a smaller change in the water levels in the fjord than a depth decrease. This is because the greater depths mean a faster water level rise inside the channel and because of this a smaller pressure difference between the two ends of the channel.

\section{Sensitivity for a Change of the Level of the Sands East of the Channel}

Most of the longshore sediment transport into the channel is deposited on the sands east of the channel. Because low depth bathymetrical surveys are difficult to carry out the quality of the bathymetric data is lower than for the rest of the data. It is therefore interesting to know what an error in the level of the sands means for the results of the modelling. In Table 2 the results are shown for situations with $20 \mathrm{~cm}$ lower and higher sands.

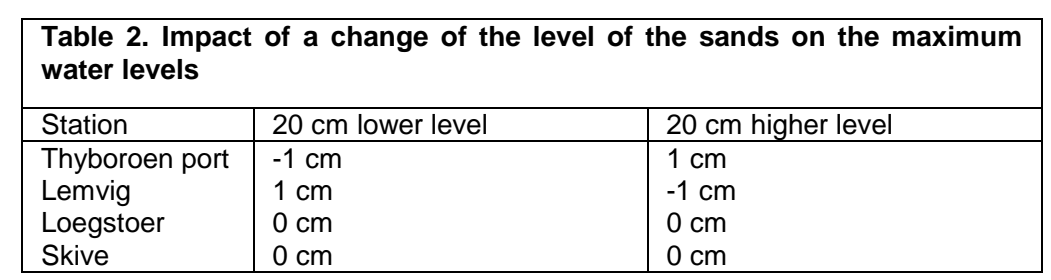

A change of the level of the sands only has a small influence on the high water levels in the fjord. The weak effect is because most of the water transport between the North Sea and the Limfjord goes through the channels between the sands. 


\section{Sensitivity for a Change of the Depth of the Channels between the Sands}

As indicated in Table 2 the water transport goes through the channels between the sands instead of over the sands. In the modelling the channel depths are increased and reduced by $20 \%$ respectively. The results are shown in Table 3.

\begin{tabular}{|c|c|c|}
\hline Station & Depths increased by $20 \%$ & Depths reduced by $20 \%$ \\
\hline $\begin{array}{l}\text { Thyboroen port } \\
\text { Lemvig } \\
\text { Logstoer } \\
\text { Skive }\end{array}$ & $\begin{array}{l}-4 \mathrm{~cm} \\
2 \mathrm{~cm} \\
0 \mathrm{~cm} \\
1 \mathrm{~cm}\end{array}$ & $\begin{array}{l}6 \mathrm{~cm} \\
-3 \mathrm{~cm} \\
0 \mathrm{~cm} \\
-2 \mathrm{~cm}\end{array}$ \\
\hline
\end{tabular}

The effect in the port of Thyboroen is opposite to the others because it is located west of the sands and the channels. It is also seen that the effect is larger to the west of Oddesund than to the east, see Fig. 1.

\section{Sensitivity to a Change in Storm Intensity}

Due to global warming it is expected that future storms will be more severe with higher water levels, longer duration and higher wind velocities. In Table 4 some of the results are shown for a change in these parameters.

\begin{tabular}{|c|c|c|c|}
\hline Station & $\begin{array}{l}20 \% \text { higher water } \\
\text { level in the sea }\end{array}$ & $\begin{array}{l}30 \% \text { longer storm } \\
\text { duration }\end{array}$ & $\begin{array}{l}10 \% \text { higher wind } \\
\text { velocities }\end{array}$ \\
\hline $\begin{array}{l}\text { Thyboroen port } \\
\text { Lemvig } \\
\text { Logstoer } \\
\text { Skive }\end{array}$ & $\begin{array}{l}33 \mathrm{~cm} \\
33 \mathrm{~cm} \\
16 \mathrm{~cm} \\
23 \mathrm{~cm}\end{array}$ & $\begin{array}{l}1 \mathrm{~cm} \\
5 \mathrm{~cm} \\
6 \mathrm{~cm} \\
13 \mathrm{~cm}\end{array}$ & $\begin{array}{l}-3 \mathrm{~cm} \\
-3 \mathrm{~cm} \\
32 \mathrm{~cm} \\
6 \mathrm{~cm}\end{array}$ \\
\hline
\end{tabular}

Higher water levels in the sea have the largest effect west of Oddesund. For the other two parameter changes the effect is largest east of Oddesund.

\section{Sensitivity to a Change in Mean Water Levels}

Global warming will cause a rise in mean sea levels. The effect this will have on high water levels for sea level rises of 25, 50 and $100 \mathrm{~cm}$ has therefore been examined, see Table 5 .

\begin{tabular}{|c|c|c|c|}
\hline Station & $25 \mathrm{~cm}$ rise & $50 \mathrm{~cm}$ rise & $100 \mathrm{~cm}$ rise \\
\hline Thyboroen port & $-3 \mathrm{~cm}$ & $-5 \mathrm{~cm}$ & $-8 \mathrm{~cm}$ \\
\hline Lemvig & $2 \mathrm{~cm}$ & $4 \mathrm{~cm}$ & $6 \mathrm{~cm}$ \\
\hline Logstoer & $-2 \mathrm{~cm}$ & $-4 \mathrm{~cm}$ & $-7 \mathrm{~cm}$ \\
\hline Skive & $1 \mathrm{~cm}$ & $1 \mathrm{~cm}$ & $2 \mathrm{~cm}$ \\
\hline
\end{tabular}

The changes are relative to the new mean water level and it appears that they are relatively small.

\section{PREPARATION OF HIGH WATER STATISTICS WITH THE CHANNEL BATHYMETRY IN 1958, 2005 AND 2060}

\section{Introduction}

To quantify the effect of the Thyboroen channel changes on the high water levels in the Limfjord, modelling with the six calibration storms was carried out using channel bathymetries from 1958, 2005 and 2060. The 2060 bathymetry was constructed by extrapolating the development between the first two mentioned bathymetries.

A comparison of the results for the 1958 and the 2005 bathymetry gives the following increases for the six maximum water levels:

- Lemvig: 21-40 cm with a mean value of $31 \mathrm{~cm}$.

- Loegstoer: 6-19 cm with a mean value of $14 \mathrm{~cm}$.

- Skive: 7-19 $\mathrm{cm}$ with a mean value of $14 \mathrm{~cm}$. 
After modelling with the constructed 2060 bathymetry the following increases were registered compared to 2005:

- Lemvig: 8-18 cm with a mean value of $15 \mathrm{~cm}$.

- Loegstoer: 1-8 $\mathrm{cm}$ with a mean value of $5 \mathrm{~cm}$.

- Skive: $1-8 \mathrm{~cm}$ with a mean value of $6 \mathrm{~cm}$.

These changes are of such a size that it was decided to carry out a comprehensive detailed analysis of the resulting changes of the high water statistics for 20 stations in the western part of the Limfjord.

\section{New High Water Statistics}

The hydrodynamic model is used to prepare high water statistics for 20 stations in the western part of the Limfjord according to the channel bathymetries in 1958, 2005 and 2060. These new statistics will be independent of the ongoing change of the channel.

In the model 31 storms from a period of 33 years are simulated. For each of the 20 stations the maximum water level for each of the 31 storms is registered. Of these 31 high water levels the 20 highest were used to prepare the new high water statistics.

Of the 20 stations four stations differ. In Thyboroen, Lemvig, Loegstoer and Skive there are registered maximum water levels for the simulated storms. Instead of preparing the new statistics based on the modelled extremes the measured data is corrected based on the simulations. In this way the risk of a systematic error is eliminated.

In table 6 the water level with a return period of 100 years is shown for the four stations as it would be with the channel configuration in 1958, 2005 and 2060. The figures are without a contribution from the sea level rise. The reason for the high water level in Thyboroen with the 1958 channel bathymetry is that the smallest cross sectional area at that time was located at Svanholm south east of the port.

\begin{tabular}{|l|l|l|l|}
\hline \multicolumn{4}{|l|}{ Table 6. Water level with a return period of 100 years } \\
\hline Station & $1958-$-channel & 2005 -channel & 2060 -channel \\
\hline Thyboroen port & $1,96 \mathrm{~m}$ & $1,96 \mathrm{~m}$ & $2,11 \mathrm{~m}$ \\
Lemvig & $1,73 \mathrm{~m}$ & $1,99 \mathrm{~m}$ & $2,38 \mathrm{~m}$ \\
Logstoer & $2,02 \mathrm{~m}$ & $2,03 \mathrm{~m}$ & $2,20 \mathrm{~m}$ \\
Skive & $1,83 \mathrm{~m}$ & $1,97 \mathrm{~m}$ & $2,09 \mathrm{~m}$ \\
\hline
\end{tabular}

\section{THE DAMAGE POTENTIAL IN THE WESTERN LIMFJORD}

\section{Introduction}

Based on the results of the described investigations it has to be considered as a fact that the maximum water levels during storms have increased in the past and will continue to increase in the future because of the development of the Thyboroen channel. Additionally the expected climate change will increase this tendency further. Consequently the probability for inundation will increase if nothing is done. In the following section the damage potential around the western Limfjord is described.

\section{The Damage Potential}

The area around the Limfjord west of Loegstoer is generally a rural area. However, there are six towns with between 5,000 and 20,000 inhabitants.

Based on available statistical data the property values below different levels have been summed up. The results are shown in Table 7 for levels of $2.0 \mathrm{~m}$ and $2.5 \mathrm{~m}$.

\begin{tabular}{|l|c|c|}
\hline $\begin{array}{l}\text { Table 7. The damage potential below } 2.0 \text { and } 2.5 \\
\text { (mill. Euro) }\end{array}$ \\
\hline Type & Below $2.0 \mathrm{~m}$ & Below $2.5 \mathrm{~m}$ \\
\hline Commercial buildings & 381 & 587 \\
Residental buildings & 416 & 541 \\
Holiday houses & 204 & 298 \\
Cultivated areas & 93 & $\frac{116}{1542}$ \\
Total & 1094 & \\
\hline
\end{tabular}

Today the coasts along the western Limfjord are protected for water levels up to a return period of about 50 years. This means a level of $1.80 \mathrm{~m}$. 


\section{ALTERNATIVE SOLUTIONS TO THE HIGH WATER PROBLEM IN THE LIMFJORD}

A continuation of the development up to now means higher water levels during storms in the western Limfjord and a higher damage potential. To combat this challenge there are two options. One is to accept the larger inflow at Thyboroen and the higher storm water levels in the fjord and instead protect the vulnerable stretches along the fjord against the high water levels. The other strategy is to reduce the inflow at Thyboroen by reducing the channels cross sectional area. Of course a combination of these two strategies could also be a possibility. The different proposals are described below.

The Danish Coastal Authority decided from the beginning to include nearly all possible solutions in the analysis. Options that are politically unrealistic due to their cost have also been included. The reason for this choice is that many stakeholders in Denmark have an opinion about how to solve the problem. For instance a solution with a dam has been regularly promoted since the 1930's.

The different possible solutions have been evaluated according to a number of different parameters. Besides the effect on the extreme water levels, effects such as environmental impact, navigational changes, the need for maintenance dredging and the impact on the sediment transport have also been evaluated. This evaluation has been kept at a screening level. In the presentation of the proposals below only the most important effects according to the evaluation parameters are mentioned.

Besides the increase in the extreme water levels due to the channel development the analysis presupposes a relative sea level rise of $24 \mathrm{~cm}$ in 2060 .

\section{PROTECTION OF THE FLOOD PRONE AREAS}

The channel development means 10-40 cm higher storm water levels in 2060 and when the sea level rise is included the future dikes should be able to protect against $0.6 \mathrm{~m}$ higher extreme water levels. It will be necessary to build $180 \mathrm{~km}$ new dikes and to heighten the $90 \mathrm{~km}$ of existing dikes and high water walls. The expenses are estimated to be 70 mill. Euro.

\section{REDUCTION OF THE INFLOW TO THE LIMFJORD}

\section{Narrowing Between the Corner Groynes at the Channel West End}

In Fig. 6 a possible solution is shown where the groyne no. 59 is extended by $600 \mathrm{~m}$. The modelling with MIKE 21 has shown that this is approximately the correct extension length required to maintain a constant inflow as it is today. The extension expense will be about 37 mill. Euro.

To produce a very smooth change of the environmental conditions in the fjord the groyne extension could be carried out in for instance three stages. The extension will stop most of the longshore sediment transport into the channel from the south. This means a much reduced need for nourishment at the southern land spit. Less accretion in the channel in front of the port will reduce the need for maintenance dredging. Advantageously for the environment in the Limfjord conditions will remain unchanged.

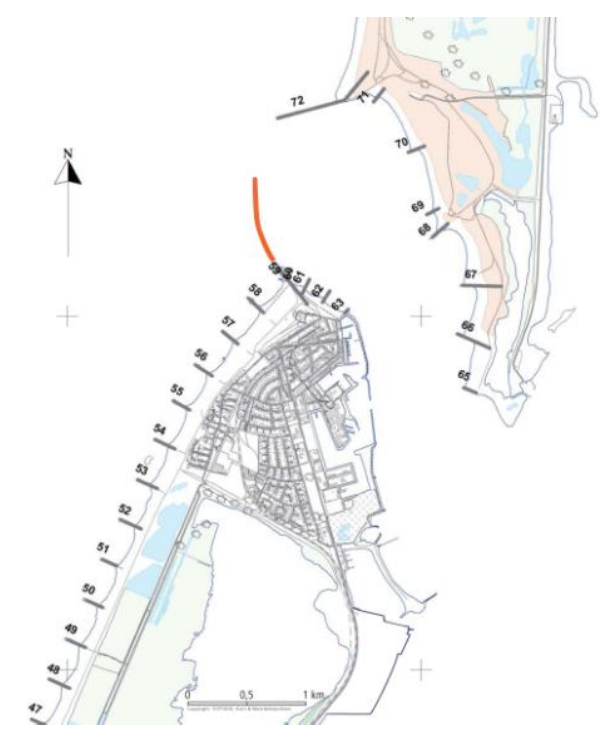

Figure 6. Extension of groyne 59. 


\section{Narrowing between the Groynes in the Channel}

In Fig. 7 a possible solution is shown where groyne no. 63 in the channel is extended to an opening width of about $500 \mathrm{~m}$. The extension will cost approximately 25 mill. Euro.

The groyne extension will not stop most of the longshore sediment transport into the channel as was the case for the former proposal. For the environment in the Limfjord the conditions will stay as they are today.

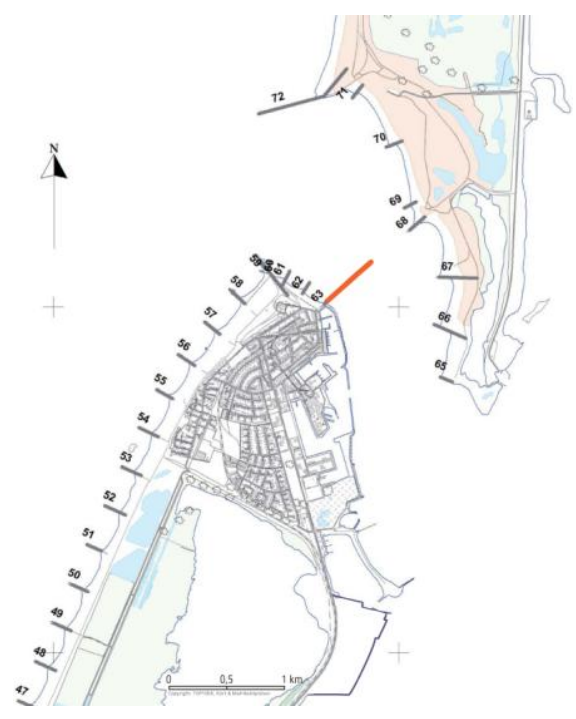

Figure 7. Extension of a groyne in the channel.

\section{Advance of the Port Entrance}

In the master plan for the Thyboroen port an advance of the port entrance is mentioned, see Fig. 8 . The expense of this advance is estimated to be 33 mill. Euro.

The advance will reduce the channels cross section. Another advantage is that the depths at the port entrance will increase so maintenance dredging here can be avoided or reduced to a minimum. To maintain the effect of the advance it would also be necessary to stabilize the north east side of the channel.

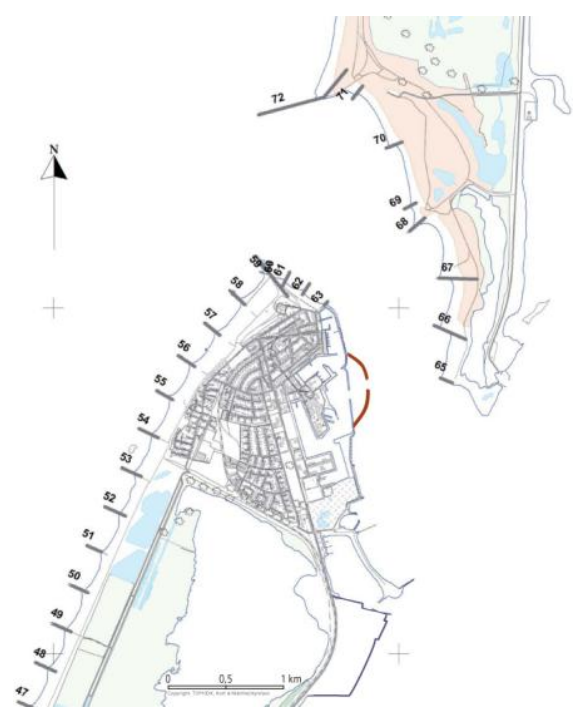

Figure 8. Advance of the port entrance. 


\section{A Stone Reef on the Sands East of the Channel}

With a stone reef as shown in Fig. 9 the central channels through the sands will be closed so only the northern and the southern channel will remain open. The $3.2 \mathrm{~km}$ long reef will cost around 50 mill. Euro.

The reef will produce the desired effect on the extreme water levels in the western Limfjord. However, the town of Thyboroen will experience higher extreme water levels.

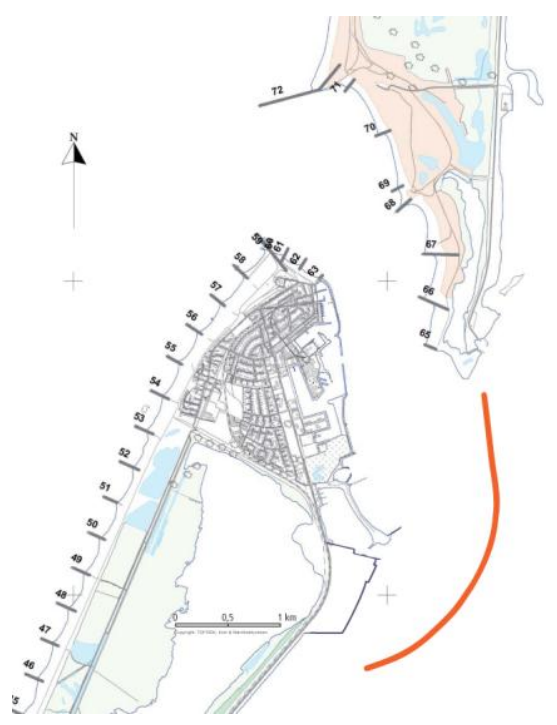

Figure 9. A stone reef east of the Thyboroen channel.

\section{A Dam with Sluices}

The dam in Fig. 10 has both a ship sluice and a through flow sluice. With a dam the longshore transport into the channel will accrete here. Therefore it is necessary to include an extension of groyne no. 59 in the proposal. The cost of this solution is estimated to be 150 mill. Euro.

This solution will also increase the maximum water levels in Thyboroen. Advantageously this solution also provides the possibility to establish a road along the top of the dam.

Figure 10. Dam with sluices.

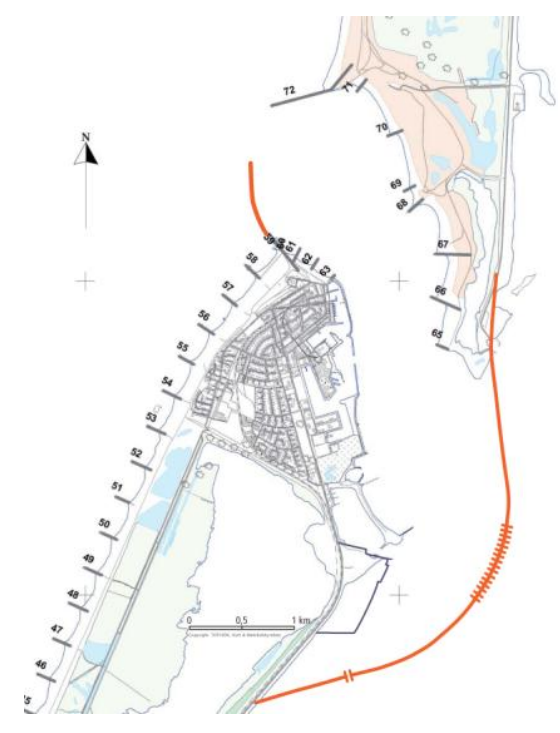

\section{High Water Barrier}

The barrier is normally lying at the bottom and is only raised when there is a high storm risk, see Fig. 11. It reduces the maximum water levels but is neutral to all the other evaluation parameters. However, it is a very expensive solution with an estimated price of $1 \mathrm{bn}$. Euro. 


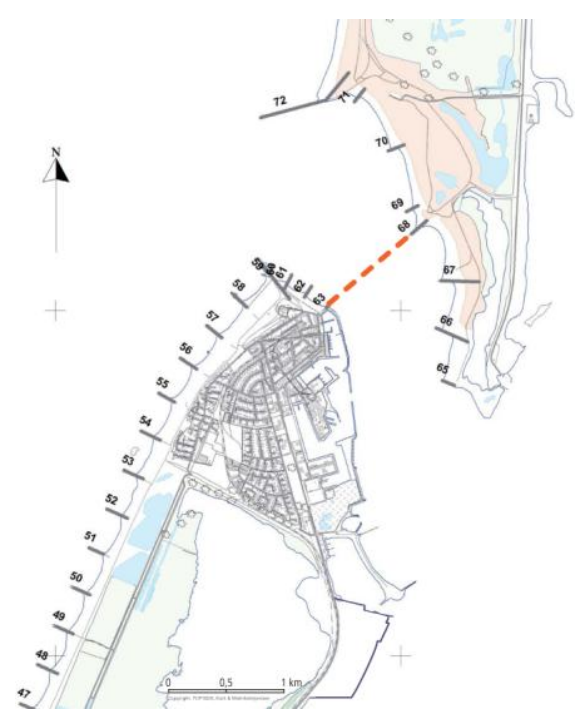

Figure 11. A high water barrier in the channel.

\section{THE FUTURE PROCESS}

Based on an evaluation of the above mentioned possibilities The Danish Coastal Authority recommends the solution with a narrowing of the west end of the channel created by extending the corner groyne, see Fig. 6. This solution reduces the future water levels in the fjord and in the town of Thyboroen. Besides this maintenance dredging at the port entrance will be reduced and the navigational conditions in the channel will be generally improved. Another great advantage is the reduced need for nourishment at the southern land spit because coastal retreat along this section of coast will be greatly reduced. It is also a good solution for the environment in the Limfjord because the conditions here will remain unchanged.

A report with recommendations on how to reduce the inflow into the Limfjord has been delivered to the Danish Ministry of Transport in August 2012. The ministry will then make a decision based on these recommendations. If the suggested solution is chosen pilot studies will be initiated and a detailed project prepared. The project should reach completion within the next 10 years.

\section{REFERENCES}

Bijsterbosch, L.W.W. 2003. Influence of relative sea-level rise on tidal inlets, M.Sc.-thesis, Delft University of Technology and WL, Delft Hydraulics Report Z2958

Sorensen, C., and S.M. Ingvardsen. 2007. Extreme sea level statistics for Denmark, 2007. Kystdirektoratet 